\title{
Esterase profile in a pyrethroid-resistant Brazilian strain of the cattle tick Boophilus microplus (Acari, Ixodidae)
}

\author{
Milla Alves Baffi ${ }^{1}$, Cícero Donizete Pereira ${ }^{1}$, Guilherme Rocha Lino de Souza ${ }^{1}$, Ana Maria Bonetti ${ }^{1}$, \\ Carlos Roberto Ceron ${ }^{2}$ and Luiz Ricardo Gourlart ${ }^{1}$ \\ ${ }^{1}$ Universidade Federal de Uberlândia, Instituto de Genética e Bioquímica, Laboratório de Genética, \\ Uberlândia, $M G$, Brazil. \\ ${ }^{2}$ Universidade Estadual Paulista, Departamento de Química e Ciências Ambientais, \\ Laboratório de Genética e Bioquímica, São José do Rio Preto, SP, Brazil.
}

\begin{abstract}
The cattle tick Boophilus microplus causes great damage in livestock and is considered one of the most important tropical ectoparasites. The traditional method of control is based on the intensive use of pesticides, however the indiscriminate use of these compounds over the years has led to the selection of resistant ticks. Hydrolases, particularly esterases (EST), have been reported to be associated with acaricide resistance in $B$. microplus. We compared the esterase profile of susceptible and cypermethrin-resistant strains of adult $B$. microplus and a pyrethroid susceptible reference strain (the Mozzo strain) using polyacrylamide gel electrophoresis and specific staining. The electrophoretic profiles of protein extracts revealed the presence of four regions with esterase activity in the cypermethrin-resistant strain and three of these regions in the susceptible strains. The bands were numbered EST-1 to EST-4 in sequence (starting from the anode) according to their decrease in negative charge. The EST-1A and EST-1B enzymes were detected only in the resistant strain. The inhibition studies with eserine sulfate, copper sulfate, $p$ - p-chloromercuribenzoate (pCMB), malathion and phenylmethylsulfonyl fluoride (PMSF) indicated that the EST-1A and EST-1B enzymes belong to the acetylcholinesterase class and are probably associated with resistance to acaricides in this Brazilian resistant strain of $B$. microplus.
\end{abstract}

Key words: Boophilus microplus, pesticides, resistance, esterases.

Received: September 24, 2004; Accepted: May 31, 2005.

The cattle tick Boophilus microplus is one of the most important ectoparasites of livestock, both in Brazil and in the tropics and subtropics in general. According to the Brazilian Agriculture Ministry B. microplus is responsible for losses in the order of one billion dollars a year (Horn, 1984). In Brazil, this parasite causes $65 \%$ of direct damage and $35 \%$ of indirect damage to cattle raising. Direct damage includes losses in milk production, natality and weight along with increased mortality and acaricide consumption as well as damage to the leather industry due to hide punctures by this tick. Indirect damages are due to the fact that $B$. microplus also acts as a disease vector transmitting the causative agents of Babesiosis and Anaplasmosis (Jongejan and Uilenberg, 1994).

Acaricides such as pyrethroids (PI) and organophosphates (OP) are currently the most used method of tick control but the indiscriminate use of these compounds over

Send correspondence to Milla Alves Baffi. Universidade Federal de Uberlândia, Instituto de Genética e Bioquímica, Laboratório de Genética, Campus Umuarama, Av. Acre s/n, bloco 2E, sala 33, 38405902 Uberlândia, MG, Brazil. E-mail: millabaffi@yahoo.com.br. the years has led to the selection of resistant ticks. Resistance in arthropods can be attributed to several mechanisms, including reduction in pesticide absorption, enhanced metabolic detoxification by esterases, oxidases and glutathione S-transferases and also pesticide target insensivity (He et al., 2002). Currently, the genetic origin of pesticide resistance has been widely studied and some authors have shown that this phenomenon can be due to gene amplification and point mutations in resistance- related genes (Hemingway, 2000).

Among the known metabolic resistance mechanisms overexpression of esterase enzymes through gene amplification has been extensively reported in the aphid Myzus persicae (Devonshire et al., 1993). Mutero et al. (1994) have identified point mutations in the acetylcholinesterase gene (AChE) in mutant strains of Drosophila melanogaster resistant to organophosphates and carbamates and have demonstrated that high levels of resistance can be the result of a large number of mutations at the active site of this enzyme. Point mutations can also occur in the gamma amino benzoic acid (GABA) receptor subunit gene, the sodium 
channel gene and the oxidases and glutathione Stransferases genes (Hemingway et al, 2002).

Among the esterases, carboxylesterases and acetylcholinesterases have been associated with pesticide resistance in arthropods. In B. microplus, the resistance mechanisms associated with esterase detoxification have been investigated by several authors. Baxter and Barker (2002) have demonstrated the relationship between the resistance to organophosphates and enhanced AChE activity in Australian B. microplus ticks and Jamroz et al. (2000) have shown increased carboxylesterase activity in a resistant pyrethroid Mexican strain of B. microplus ticks. Carboxylesterase and acetylcholinesterase gene point mutations have also been detected in these ticks (Hernandez et al., 2000, 2002). In this paper we report the biochemical comparison of esterase patterns between engorged females resistant and sensitive to cypermethrin with the aim of identifying an esterases-associated acaricide resistance mechanism in a population of Brazilian B. microplus cattle ticks.

Experimental tick strains were obtained from a field resistance test with an adult tick population in the Vallée S/A Experimental Farm (Uberlandia, MG, Brazil), using $2.5 \%$ cypermethrin as acaricide. A highly infested calf (approximately 500 ticks) aged one year old was pulverized with the acaricide and the engorged adult female ticks (approximately 150) that fell from the calf up to three hours after pulverization were collected and considered susceptible (S). The ticks (approximately 350) which remained attached to the calf after $24 \mathrm{~h}$ were also collected and considered resistant (R). We also used a susceptible reference strain (Mozzo strain) from Uruguay which had never been exposed to pesticides and had been maintained in the Valeé Experimental Farm. A longitudinal incision was made in the abdomen of each tick and the excess blood eluted with ultrapure water and the prepared ticks were frozen at $-80{ }^{\circ} \mathrm{C}$. For esterase pattern analysis, 30 ticks from each from each strain (Mozzo, susceptible and resistant) were used and individually analyzed.

The frozen ticks were individually squashed in liquid nitrogen and homogenized in buffer containing $10 \mathrm{mM}$ of sodium phosphate $(\mathrm{pH} 6.5), 20 \%(\mathrm{w} / \mathrm{v})$ sucrose, $1 \mathrm{mM}$ EDTA, and $0.5 \%(\mathrm{v} / \mathrm{v})$ Triton X-100. Extracts were centrifuged at $4{ }^{\circ} \mathrm{C}, 15.000 \mathrm{~g}$ for $10 \mathrm{~min}$ and supernatants decanted and stored at $-80{ }^{\circ} \mathrm{C}$. Extracted protein from tick homogenates was quantified at $595 \mathrm{~nm}$ using the Bradford (1976) method and the average protein concentration of each homogenate determined from a standard curve using bovine serum albumin as the standard protein.

Non-denaturing polyacrylamide gel electrophoresis (PAGE) was performed using the Laemmli (1970) buffer system without sodium dodecil sulfate (SDS) and a gel system consisting of a $4 \%(\mathrm{w} / \mathrm{v})$ stacking gel and a $12 \%(\mathrm{w} / \mathrm{v})$ separating gel. Electrophoresis was conducted at a constant current of $40 \mathrm{~mA}$ for $4 \mathrm{~h}$ at $4{ }^{\circ} \mathrm{C}$ in pre-chilled buffer containing $87 \mathrm{mM}$ Tris and $13 \mathrm{mM}$ glycine (pH 8.3). Esterase activity of $100 \mu \mathrm{g}$ of extracted protein per sample was detected by the method of Steiner and Johnson (1973), by pre-incubation of the gel in $100 \mathrm{mM}$ sodium phosphate buffer ( $\mathrm{pH} 6.5$ ) for $30 \mathrm{~min}$ at $37^{\circ} \mathrm{C}$, followed by incubation in $100 \mathrm{mM}$ phosphate buffer containing $3.2 \mathrm{mM} \alpha$ or $\beta$ naphthyl acetate and $2.4 \mathrm{mM}$ Fast Blue R/R Salt (SIGMA) for $60 \mathrm{~min}$ in the dark at $37^{\circ} \mathrm{C}$. The $\alpha$ and $\beta$-naphthyl acetate stock solutions were prepared in $1 \mathrm{~mL}$ of acetone to aid their solubility in the phosphate buffer.

Inhibition tests for the biochemical characterization of esterases used $1.0 \mathrm{mM}$ copper sulfate, $1.0 \mathrm{mM}$ p-chloromercuribenzoate (pCMB), $0.4 \mathrm{mM}$ malathion, $1.0 \mathrm{mM}$ eserine sulfate and $1.0 \mathrm{mM}$ phenylmethylsulfonyl fluoride (PMSF). Gels were pre-incubated for $30 \mathrm{~min}$ in the dark in phosphate buffer (100 mM, pH 6.5) containing inhibitor and then stained for esterase activity in the presence of inhibitor. PMSF was dissolved in $1 \mathrm{~mL}$ methanol and pCMB in $1 \mathrm{~mL}$ of $100 \mathrm{mM} \mathrm{NaOH}, \mathrm{pH} 8.0$, prior to use. Eserine sulfate and copper sulfate were added directly to the pre-soaking and staining solution and commercial malathion solution (Vallee S/A) was added to give a final concentration of $0.4 \mathrm{mM}$ in pre-incubation and staining.

Direct observation of the gels revealed four regions displaying esterase activity against the $\alpha$-naphthyl acetate in this Brazilian B. microplus population and were numbered consecutively as EST-1 to EST-4, according to their migration from the anode (Figure 1). The EST-1A and EST-1B enzymes were observed exclusively in the resistant strain $(\mathrm{R})$ whereas the other enzymes were detected in all the samples analyzed. Figure 1 also shows that the Mozzo strain (M) and the cypermethrin susceptible field strain (S) presented the same esterase band profile.

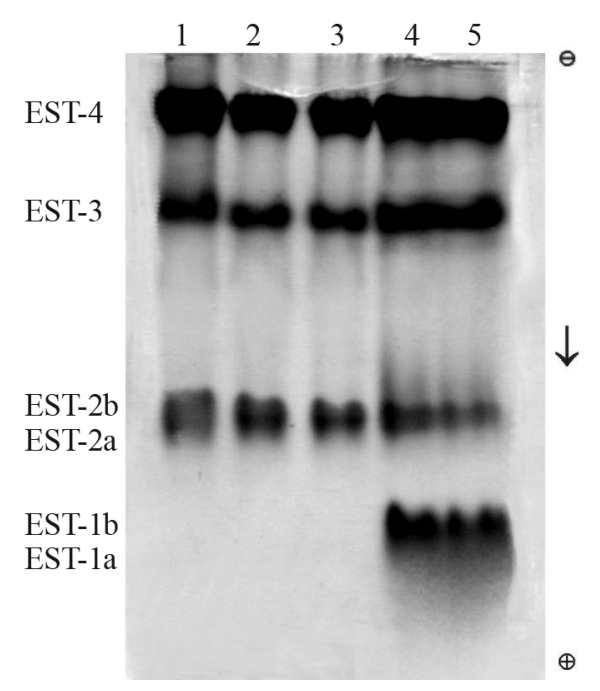

Figure 1 - Gel profile of general esterase hydrolytic activity in an experimental Boophilus microplus tick strain from Brazil. Protein extracts were separated on $12 \%(\mathrm{w} / \mathrm{v})$ polyacrylamide gel and stained in the presence of $\alpha$-naphthyl acetate. Lanes: (1) sensitive Mozzo reference strain; (2-3) cypermethrin susceptible strain (S); (4-5) cypermethrin resistant strain (R) as judged by the field resistance test described in the text. 
The identified enzymes also displayed activity against $\beta$-naphthyl acetate, although the esterase pattern was the same as that observed when $\alpha$-naphthyl acetate was used (data not shown). When the gels were stained simultaneously in the presence of both substrates they stained black, indicating preferential hydrolysis by $\alpha$-naphthyl acetate (data not shown).

The action of some inhibitors on the esterases from the Brazilian and Mozzo B. Microplus strains was also determined. The samples of resistant, sensitive and Mozzo ticks were submitted to electrophoresis and immediately after were pre-incubated and stained for esterase activity in the presence of inhibitors. Table 1 shows the effect of the inhibitors on the esterase bands, and the degree of inhibition being classified according to decrease in band intensity. None of the enzymes were affected by copper sulfate, which presented a slightly activating effect on all the enzymes tested. We also found that $\mathrm{pCMB}$ had no inhibitory effect on any of the bands while eserine sulfate has completely inhibited EST-1A and EST-1B in resistant ticks (R). The EST-2A and EST-2B enzymes of the sensitive strains ( $\mathrm{M}$ and $\mathrm{S}$ ) were strongly inhibited by eserine but were only partially affected in the resistant strain, while the other enzymes were not inhibited by eserine. When the gels were treated with malathion we found that all the enzymes were heavily inhibited in all samples, while PMSF totally inhibited EST-1A, 1B, 3 and 4 activity and, to a lesser extention, EST-2A and 2B.

The $\alpha$ - and $\beta$-esterases have been extensively studied in insects and are known to be involved in different physiological processes, such as regulation of juvenile hormone levels (Kort and Granger, 1981), reproduction (Richmond et al., 1980), functioning of the nervous system and development of resistance to insecticides (Guillemaud et al., 1997).

The electrophoretic profiles (Figure 1) revealed the presence of four regions with esterase activity in the cypermethrin-resistant strain $(\mathrm{R})$ and three of these regions in the susceptible strains ( $\mathrm{M}$ and $\mathrm{S}$ ). The results also demonstrated that there were no differences in the esterase pattern between the samples from the Mozzo strain (M) and those from the cypermethrin susceptible field strain (S). The Mozzo strain has been maintained in the Vallée S/A Experimental Farm for several generations as a susceptible reference strain in the absence of pesticide selection pressure. de Souza (2001) analyzed these same populations using Amplified Fragment Length Polymorphism markers (AFLP) and observed a genetic similarity between the Mozzo and field sensitive strains and also that pyrethroid resistant ticks presented a higher variability in relation to the sensitive ticks.

The number of esterase loci has been associated with adaptation to a large number of substrates which these enzymes act on due to the diverse natural diet of the ticks. The reduced number of esterase enzymes observed in this population of cattle ticks can be related to the restricted habitat and nutrition of such ticks. Villarino et al. (2003) purified three $\beta$-naphthyl acetate hydrolyzing esterases from the integument of adult Texan B. microplus ticks.

Our data differs from a study of a population of Mexican B. microplus larvae which detected 22 regions with $\alpha$-naphthyl acetate esterase activity (Jamroz et al., 2000), but it should be remembered that in our case we used engorged adult females and because tick development is controlled by direct and indirect changes in the pattern of gene expression esterase profiles can be very different at different stages in the life cycle. We are at present carrying out a comparative analysis of the esterase profile in the different stages of the life cycle of $B$. microplus and this may clarify these questions and contribute more information.

The inhibition tests for biochemical characterization of esterases in insects have been important to decipher the different physiological processes in which esterases act on.

Table 1 - Inhibitor effects on esterase activity in sensitive and cypermethrin-resistant Brazilian B. microplus ticks. (-) absence of inhibition; $(+,++,+++$, ++++ ) increasing levels of inhibition.

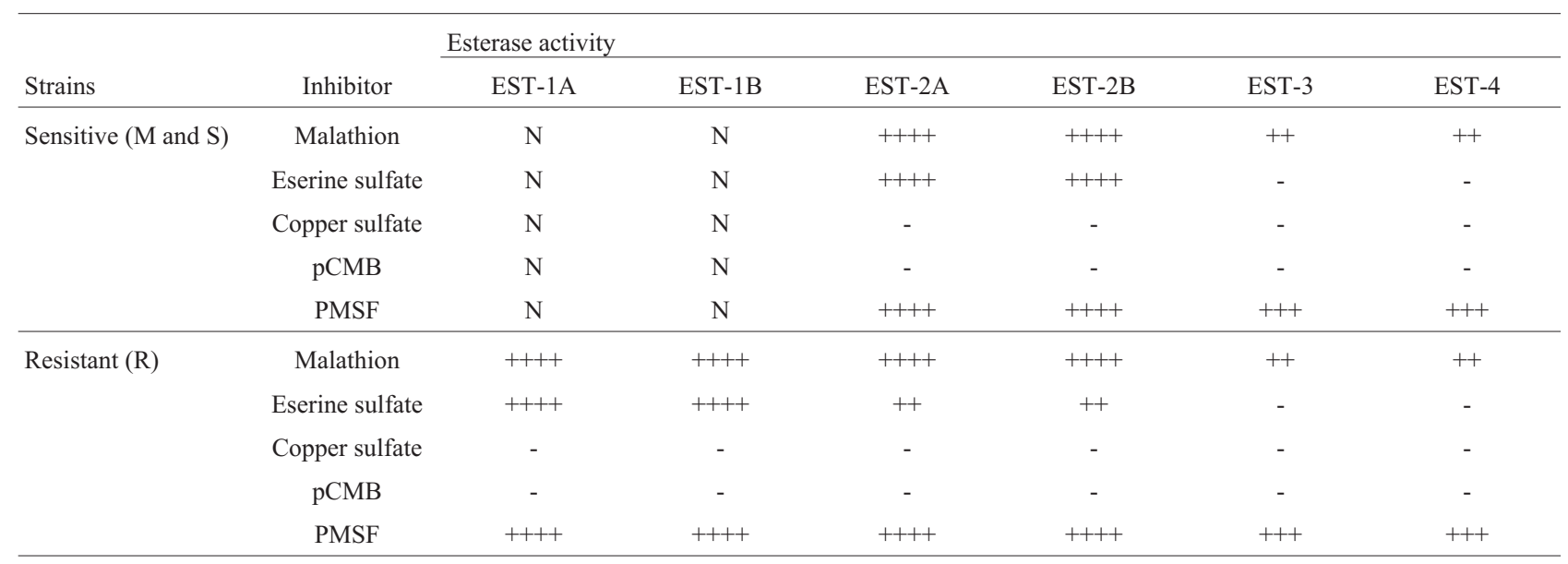

Key: $(\mathrm{N})$ : not detected in these strains (M and S). 
Our inhibition assays show that PMSF almost totally inhibited all the bands. The PMSF is a serine-hydrolase inhibitor, suggesting that these enzymes contain serine residues in their active sites. These observations suggest that EST-4 may be a carboxylesterase containing an active serine, since this enzyme was totally inhibited by PMSF and partially by malathion but was resistant to eserine sulfate and copper sulfate. In relation to EST-3, this enzyme was inhibited by malathion and PMSF but was resistant to eserine sulfate which means that it can also be classified as a carboxylesterase containing an active serine residue. Carboxylesterases can serve as protective role for the target acetylcholinesterases during organophosphate intoxication because the carboxylesterases are alternative phosphorylation sites (Watson and Chambers, 1996). Villarino et al. (2003) purified three esterases from the integument of resistant adult Texan B. microplus and characterized the esterases as carboxylesterases based on inhibitor effects and also identified the presence of different amounts of esterase activity in resistant and susceptible ticks. In our work, we observed no differences in these enzymes between the Mozzo, susceptible and resistant strains, so we cannot establish if these enzymes are related to resistance. We also found that EST-2A and EST-2B were totally inhibited by eserine in the sensitive strains ( $\mathrm{M}$ and $\mathrm{S}$ ) but only partially in the resistant strain $(\mathrm{R})$. This result indicates that these enzymes could be present at a higher copy number in the resistant strain, but this hypothesis can only be confirmed through a quantitative analysis. These enzymes were also strongly inhibited by malathion and almost totally by PMSF, results which putatively indicate that they represent acetylcholinesterase (AChE) activity. However, it is unlikely that these enzymes represent distinct AChEs and they probably correspond to alternative forms of AChE, since they were detected as double bands much closer to each other on the gels (Figure 1). Likewise, EST-1A and EST-1B were classified as acetylcholinesterases because they were strongly inhibited by malathion, eserine sulfate and PMSF. These bands may represent different gene products from the same allele which may have suffered glycosylation or some other kind of post-translational modification, producing esterase bands with a slightly different migration pattern. Esterases with molecular weights ranging from 66 to $68 \mathrm{kDa}$ have been attributed to differential glycosylation and associated with insecticide resistance in the brown planthopper Nilaparvata lugens (Small and Hemingway, 2000). Moreover, in Australian B. microplus strains, two AChE genes ( $A C h E 1$ and $A C h E 2)$ were identified at the synganglia and sequenced (Baxter and Barker, 2002). The AChEs (EST-1 and EST-2) detected in our work may be the products of two distinct genes which could have originated from duplication. Whether or not the specific esterase mechanisms detected in the $\mathrm{R}$ strain are identical to those found in the Australian tick strains is unknown at this point.
The partial inhibition of EST-2A and EST-2B by eserine in the $\mathrm{R}$ strain may indicate acetylcholinesterases with enhanced insensitivity to acaricide. This insensitivity suggests a AChE-mediated resistance mechanism possibly involving gene duplication and esterase overexpression. Gene duplication events have previously been proposed to explain pyrethroid resistance involving carboxylesterases in Mexican ticks (Jamroz et al., 2000).

We detected EST-1A and EST-1B enzymes only in the resistant strain (Figure 1), which may represent additional acetylcholinesterases with decreased sensitivity as an important defense mechanism used by this Brazilian $B$. microplus strain to develop cypermethrin resistance. Acetylcholinesterase is the target enzyme for the pesticide attack and an altered AChE level with enhanced metabolic detoxification was identified as the primary mechanism used by $B$. microplus to develop resistance to organophosphate pesticides in Mexican strains (Hernandez et al., 1999). Acetylcholinesterase has been identified at synapses in the central nervous system of arthropods, this enzyme terminates nerve impulses by catalyzing the hydrolysis of the neurotransmitter acetylcholine at the synaptic junction after which the nerve impulse is transmitted to the axonium membrane where it stimulates the opening of the sodium channels. Pyrethroids normally act by keeping the sodium channels open and causing death by hyperexcitation. Organophosphates and carbamates act as AChE inhibitors, and in our experiments we detected a pyrethroid resistance mechanism mediated by AChEs. It is possible that these additional AChEs compensate for the inhibitory effect of sodium channels. In addition, we used a field strain which was exposed to several types of acaricides, including pyrethroids and organophosphates over the time. This could indicate that our resistant field strain is resistant to other pesticides and that the AChEs are related to organophosphate resistance or that there is another pyrethroid resistance mechanism undetected by us.

This work is the first study describing acaricide resistance related to esterase activity in a Brazilian Boophilus microplus population. The results indicate the existence of multiple forms of resistance in these ticks. Future work will focus on the characterization of these mechanisms to provide an accurate diagnosis of resistance in order to allow more effective tick control strategies.

\section{Acknowledgments}

We thank Valleé S/A for supllying the Mozzo strain and the acaricides for the experiments. Research supported by CNPq, CAPES and UFU.

\section{References}

Baxter GD and Barker, SC (2002) Analysis of the sequence and expression of a second putative acetilcolinesterase cDNA from organophosphate-suscetible and resistant cattle ticks. Insect Biochem Mol Biol 32:815-820. 
Bradford M (1976) A rapid and sensitive method for the quantitation of microgram quantities of protein utilizing the principle of protein-dye binding. Anal Biochem 72:248-254.

de Souza GRL (2001) Variabilidade genética de marcadores AFLP em populações de carrapato Boophilus microplus induzida por carrapaticidas. Dissertação de Mestrado, Universidade Federal de Uberlândia, Uberlândia.

Devonshire AL, Williamson MS, Moores GD and Field LM (1993) Analysis of the esterase genes conferring insecticide resistance in peach-potato aphid, Myzus perspicae. Biochem J 294:569-574.

Guillemaud T, Makate N, Raymond M, Hirst B and Callghan A (1997) Esterase gene amplification in Culex pipiensis. Insect Mol Biol 6:319-327.

He H, Chen AC, Davey RB and Ivie GW (2002) Molecular cloning and nucleotide sequence of a new P450 gene, CYP319A1, from the cattle tick, Boophilus microplus. Insect Biochem Mol Biol 32:303-309.

Hemingway J (2000) The molecular basis of two contrasting metabolic mechanisms of insecticide resistance. Insect Biochem Mol Biol 30:1009-1015.

Hemingway J, Field L and Vontas J (2002) An overview of insecticide resistance. Science 298:96-97.

Hernandez R, He H, Chen AC, Ivie GW, George JE and Wagner GG (1999) Cloning and sequencing of a putative acetylcholinesterase cDNA from Boophilus microplus. J Med Entomol 36:764-770.

Hernandez R, He H, Chen AC, Ivie GW, Waghela SD, George JE and Wagner GG (2000) Identification of a point mutation in an esterase gene in different populations of the cattle tick, Boophilus microplus. Insect Biochem Mol Biol 30:969-977.

Hernandez R, Guerrero FD, George JE and Wagner GG (2002) Allele frequency and gene expression of a putative carboxylesterase-encoding gene in a pyrethroid resistant strain of the tick Boophilus microplus. Insect Biochem Mol Biol 32:1009-1016.

Horn SC (1984) O Couro e Seus Problemas. Sec. Dev. San. Animal, Brasília, $40 \mathrm{pp}$.

Jamroz RC, Guerrero FD, Pruett JH, Oehler DD and Miller RJ (2000) Molecular and biochemical survey of acaricide resistance mechanisms in larvae from Mexican strains of southern cattle tick. J Insect Physiol 46:685-695.

Jongejan F and Uilenberg G (1994) Ticks and control methods. Rev Sci Tech Off Int Epiz 13:1201-1226.

Kort CA and Granger NA (1981) Regulation of the juvenile hormone titer. Ann Rev Entomol 26:1-28.

Laemmli UK (1970) Cleavage of structural protein during assembly of the head of bacteriophage T4. Nature 227:680-685.

Mutero A, Pralavorio M, Bride JM and Fournier D (1994) Resistance associated point mutations in insecticide-insensitive acetylcholinesterase. Proc Natl Acad Sci 91:5922-5926.

Richmond RC, Gilbert DG, Sheehan KB, Gromko MH and Butterworth FM (1980) Esterase 6 and reproduction in Drosophila melanogaster. Science 207:1483-1485.

Small GJ and Hemingway J (2000) Differential glycosylation produces heterogeneity in elevated esterases associated with insecticide resistance in the brown planthopper Nilaparvata lugens Stål. Insect Biochem Mol Biol 30:443-453.

Steiner WWM and Johnson WE (1973) Techniques for electrophoresis of Hawaiian Drosophila US - IBP. Island Ecosyst Tech Rep 30:1-21.

Villarino MA, Waghela SD and Wagner GG (2003) Biochemical detection of esterases in the adult female integument of organophosphate-resistant Boophilus microplus (Acari, Ixodidae). J Med Entomol 40:52-57.

Watson AM and Chambers JE (1996) The effect of high and low dosages of paraoxon in beta-naphtolflavone-treated rats. J Biochem Toxicol 11:263-268.

Associate Editor: Catarina S. Takahashi 